\title{
Numerical Study on Low Reynolds Number Flows Over an Aerofoil
}

\section{Ilyas Karasu', M. Serdar Genç and H. Hakan Açikel ${ }^{2}$}

${ }^{1}$ Gaziantep University, Faculty of Aeronautics and Astronautics, 27310, Gaziantep, Turkey

${ }^{2}$ Erciyes University, Department of Energy Systems Engineering, 38039, Kayseri, Turkey

\begin{abstract}
This study is a numerical investigation on laminar separation bubble over a NACA2415 aerofoil at low Reynolds numbers and various angles of attack. The numerical results were compared with the experimental results of our previous study. Oil flow visualization technique, an external three-component balance system and pressure measurements were used for the experiments. In the experimental results, stall angle was $12^{\circ}, 13^{\circ}$ and $15^{\circ}$ for $R e=0.5 \times 10^{5}, R e=1 \times 10^{5}$ and $R e=3 \times 10^{5}$, respectively. The flow separation, reattachment and forming the laminar separation bubble were clearly seen by using the aforementioned experimental methods. It was indicated that the point of separation moved towards the leading edge as the angle of attack increased. Moreover, the flow visualization results showed that as the angle of attack increased further, the bubble burst and the separated flow was not able to reattach to the aerofoil surface, which indicated stall. In the numerical results, the transition models are shown to accurately predict the location of the separation bubble experimentally determined at lower angles of attack. Furthermore, the numerical prediction using the transition models are more successful than the turbulence model suitable for low Re number flows.
\end{abstract}

Keywords: Laminar Separation Bubble; Low Reynolds Number Aerodynamics Transition Models

\section{Introduction}

Low Reynolds number flow has gained popularity because of increasing numbers of applications of Unmanned Aerial Vehicles (UAV), Micro Air Vehicles (MAV) and wind turbines. At low Reynolds number flows, viscous effects are dominant and momentum of the flow is incapable to move downstream and adverse pressure gradient causes the laminar flow to separate, and separated flow reattach to the surface because of the transition (Figure 1). The region between laminar separation and turbulent reattachment is called as laminar separation bubble which has adverse effects on the aerofoil such as decreased lift coefficient, increased drag coefficient. It changes the moment coefficient, causing abrupt stall [1], decreasing control surface effectiveness [2] and vibration [3]. Because of the delicate nature of the flow regime, extended research on low Reynolds number aerodynamics should be conducted and also numerical models must be developed and present numerical models must be validated.

When laminar separation bubble occurs over an aerofoil, it causes changes on pressure distribution; in dead air region laminar separation bubble causes sudden increase in CP after the transition process

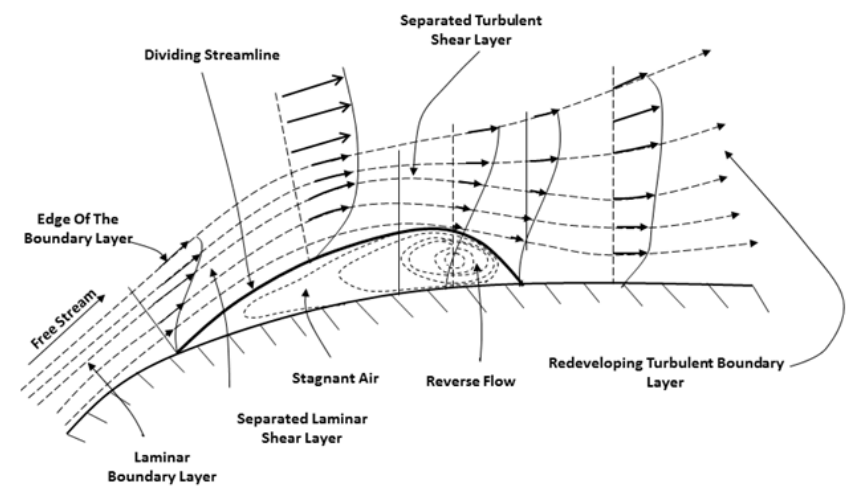

Figure 1: Section view of two dimensional short laminar separation bubble [4]. completes since the flow is more energetic the flow reattaches the surface and in this region $\mathrm{CP}$ recovers to the same value of the in viscid flow as shown in Figure 2. Laminar separation bubbles are classified as short and long bubbles $[4,5]$. For the short bubble case, the flow may reattach to the surface of the aerofoil and long bubble occurs after bursting of short bubbles and fails to reattach and this causes early stall.

In parallel with modern developments in experimental researches, in the prediction methods it has been devised to account for transition mechanisms over the aerofoils [6,7] and incorporated modern experimental and numerical means. Recently developed transport

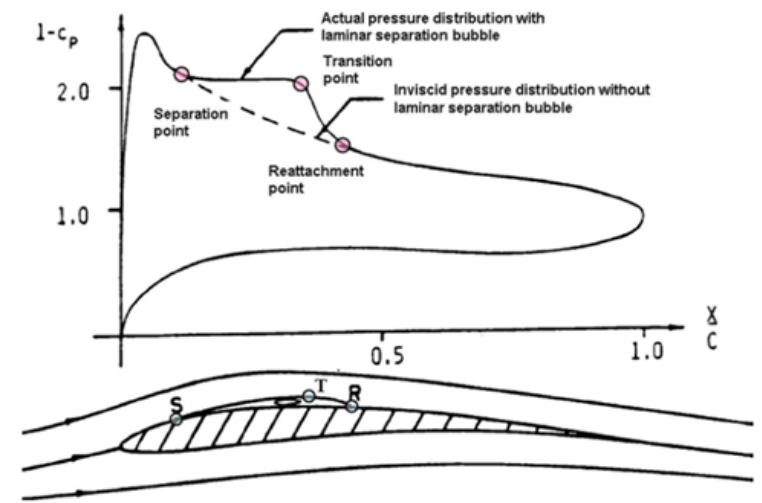

Figure 2: Pressure distribution over an aerofoil has laminar separation bubble [6]

*Corresponding author: M. Serdar Genç, Erciyes University, Department of Energy Systems Engineering, 38039, Kayseri, Turkey, Tel: 035243749 01; Fax: 0352437 57 84; E-mail: musgenc@erciyes.edu.tr

Received September 03, 2013; Accepted November 26, 2013; Published December 05, 2013

Citation: Karasu I, Genç MS, Açikel HH (2013) Numerical Study on Low Reynolds Number Flows Over an Aerofoil. J Appl Mech Eng 2: 131. doi:10.4172/21689873.1000131

Copyright: (c) 2013 Karasu I. This is an open-access article distributed under the terms of the Creative Commons Attribution License, which permits unrestricted use, distribution, and reproduction in any medium, provided the original author and source are credited. 
Citation: Karasu I, Genç MS, Açikel HH (2013) Numerical Study on Low Reynolds Number Flows Over an Aerofoil. J Appl Mech Eng 2: 131. doi:10.4172/2168-9873.1000131

equation models have helped to incorporate certain benchmark experimental data that were expressed in terms of global boundary layer parameters into current RANS based solvers. Genc et al. [8] performed experimental and numerical survey over aerofoil with leading edge slat at low Reynolds number of $2 \times 10^{5}$ using FLUENT RANS based solver. NACA2415 were used as aerofoil, and NACA22 was used as leading edge slat. In the numerical investigation, for the aerofoil without slat, $\mathrm{k}-\varepsilon$ RNG and $\mathrm{k}-\omega$ SST turbulence models, the $\mathrm{k}-\mathrm{k}_{\mathrm{L}}-\omega$ Transition and $k-\omega$ SST Transition models; and for the slat configuration $k-k_{L}-\omega$ Transition and SST Transition models were used. For the single element aerofoil, the turbulence models under predicted on the prediction laminar separation bubble, while the transition models gave the better results, moreover the $\mathrm{k}-\mathrm{k}_{\mathrm{L}}-\omega$ Transition model gave the best results. For the aerofoil with the leading edge slat, the effects of the slat on laminar separation bubble was investigated for $\alpha=8^{\circ}$, and while $\mathrm{k}-\mathrm{k}_{\mathrm{L}}-\omega$ Transition could not eliminate the bubble, SST Transition model could eliminate the bubble and showed good agreement with the surface oil visualization experiments. Genc et al. [9] also carried out an investigation flow over NACA 2415 aerofoil and effects of blowing and suction on laminar separation bubble at $\mathrm{Re}=2 \times 10^{5}$. For the numerical investigation $\mathrm{k}-\varepsilon$ RNG, $\mathrm{k}-\omega$ SST turbulence models and $\mathrm{k}-\mathrm{k}_{\mathrm{L}}-\omega$ Transition and SST Transition models were used, and when there was no blowing or suction none of the model was superior for prediction of all performance parameters, the most reasonable predictions were gained by $\mathrm{k}-\mathrm{k}_{\mathrm{L}}-\omega$ Transition model.

Catalona and Tognaccini [10] studied numerically the flow over a SD 7003 aerofoil by using k- $\omega$ SST-LR turbulence model and they concluded that this model provided satisfactory results for their investigation. Sanders et al. [11] conducted a numerical investigation over two different low pressure turbine blade aerofoil cascade configuration at Re ranging $1.5 \times 10^{4}$ to $1 \times 10^{5}$. In this investigation, $\mathrm{k}$ $\varepsilon$ and $\mathrm{k}-\omega$ SST turbulence models and $\mathrm{k}-\mathrm{k}_{\mathrm{L}}-\omega$ Transition model were used and $\mathrm{k}-\mathrm{k}_{\mathrm{L}}-\omega$ Transition model predicted better transition behavior at low Reynolds number than other two 2-D RANS method. Catalona and Tognaccini [12] presented a numerical survey over SD7003 aerofoil. In this survey RANS and LES methods were used and results were compared with each other. In the RANS computations S-A k- $\varepsilon$ -MK and k- $\omega$ BSL and k- $\omega$ SST were used as turbulence models. The performance of the k- $\omega$ SST model were investigated deeply and a modification was offered by the authors and the modified version of k- $\omega$ SST model was called k- $\omega$ SST-LR model and results of this model for $\mathrm{Re}=60000$ and $\alpha=4^{\circ}$ showed very good agreement with LES results. Chitta et al. [13] performed a numerical investigation over an elliptical aerofoil. S-A, k- $\omega$ SST, curvature-sensitive SST $\mathrm{k}-\omega-\mathrm{v}^{2}$

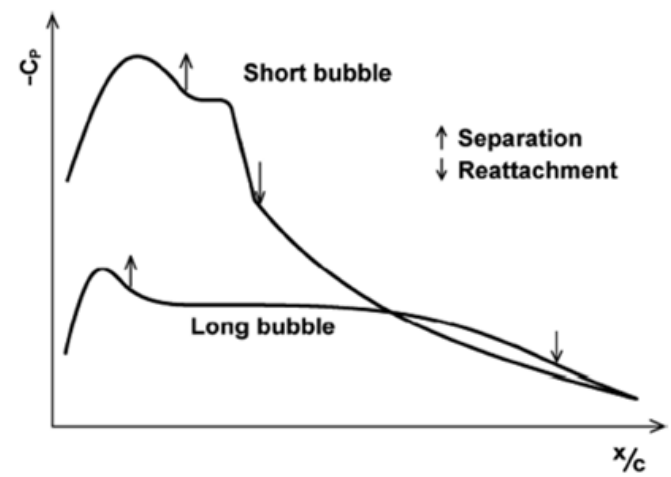

Figure 3: Pressure distribution over short and long bubble [7]

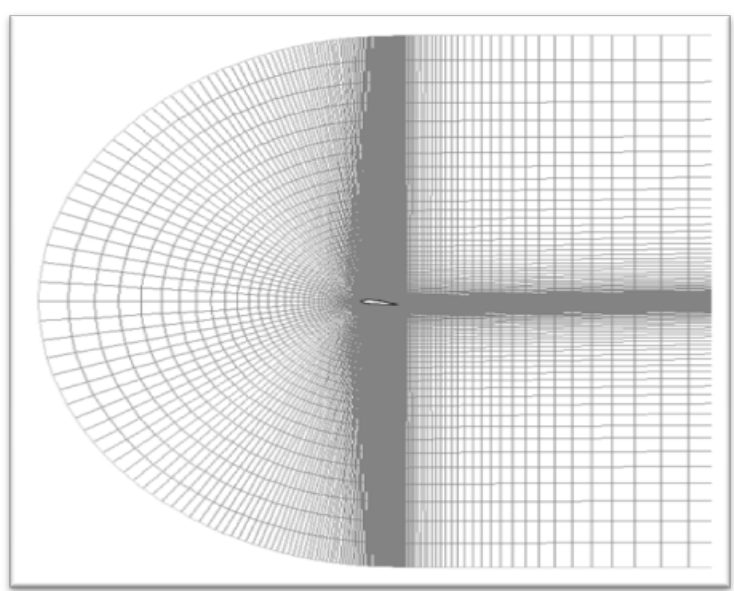

Figure 4: The mesh structure.

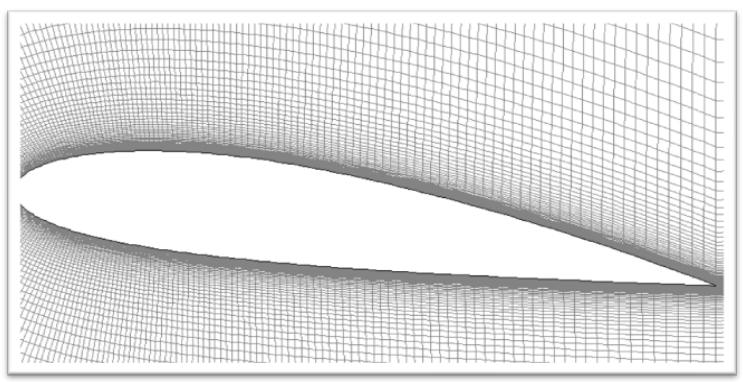

Figure 5: The detailed view of the mesh aerofoil.

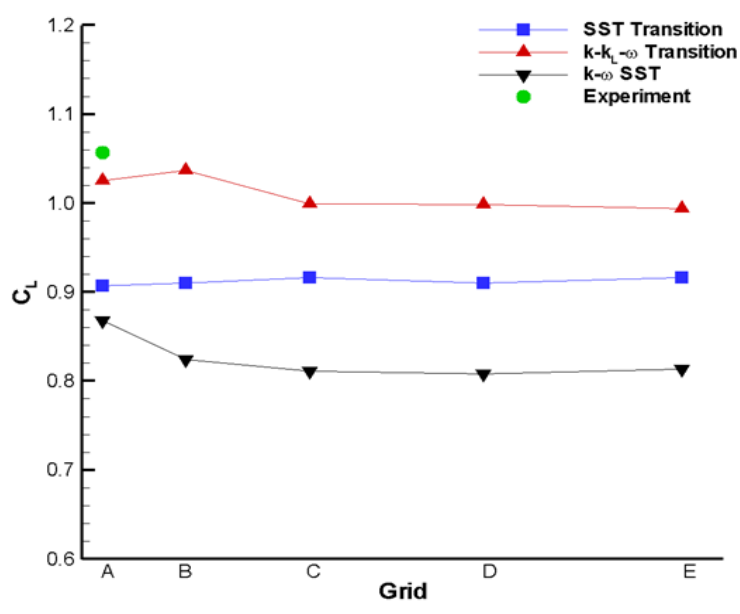

Figure 6: $C_{L}$ values obtained from different sized grids for $R e=1 \times 10^{5}$ at $\alpha=8^{\circ}$.

which was modified version of SST $\mathrm{k}-\omega$ model turbulent models and $\mathrm{k}-\mathrm{k}_{\mathrm{L}}-\omega$ and SST Transition were used. Transition models predicted lift characteristics, separation and reattachment points more accurately than the other three fully turbulent models, furthermore except curvature-sensitive SST $\mathrm{k}-\omega-\mathrm{v}^{2}$ model, none of these models could predict the stall angle correctly. Ibrahim et al. [14] carried out an experimental and numerical study over L1A aerofoils used for low 

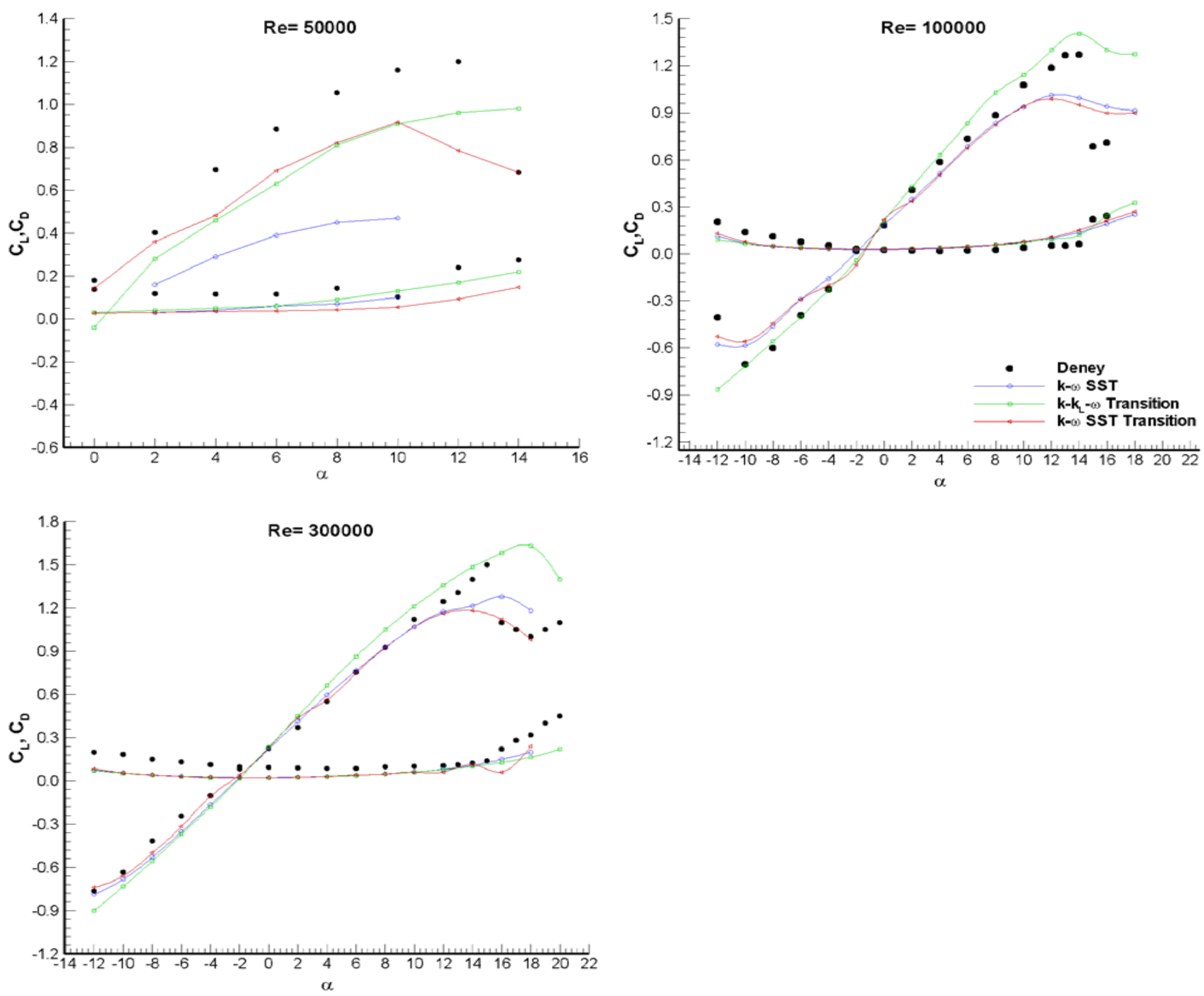

Figure 7: $C_{L}$ and $C_{D}$ coefficients of NACA 2415 aerofoil for different angles of attack and Re numbers.

pressure turbine blades of gas turbine engines at different Reynolds number ranging $2.5 \times 10^{4}$ to $3 \times 10^{5}$. In the numerical study, $\mathrm{k}-\omega \mathrm{SST}$, v2-f model turbulence models and SST Transition model were used. Their results showed that at Reynolds numbers below $1.5 \times 10^{5}$ the separated flow could not reattach but at Reynolds number higher than $1.5 \times 10^{5}$ the separated flow could reattach to surface. According to numerical results, at $\mathrm{Re}=2.5 \times 10^{4}$ and $\mathrm{Re}=1 \times 10^{5}$, SST Transition model gave best results at $\operatorname{Re}=3 \times 10^{5}$ all models gave similar results each other.

In this study, the evaluation of performance of k- $\omega$ SST turbulence

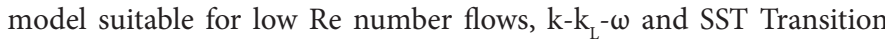
models were made based on prediction laminar separation bubble of NACA2415 at different angles of attack and Reynolds numbers. Experimental results for the validation of numerical results were taken from an experimental study performed by the authors of this study [15].

\section{Numerical Study}

\section{Solution Grid}

Structural C type grid which has 32000 cells and 32380 nodes was constructed by the GAMBIT ${ }^{\mathrm{TM}}$ software (Figures 3 and 4). The aerofoil has $180 \mathrm{~mm}$ chord (c) length. The grid extends from $-10 \mathrm{c}$ to $10 \mathrm{c}$ in the $\mathrm{x}$ direction and $-10 \mathrm{c}$ to $10 \mathrm{c}$ in the $\mathrm{y}$ direction (Figure 5). The mesh got finer around the aerofoil to ensure $\mathrm{y}^{+}$values below unity. Different sized grids such as 22000 (A), 26000 (B), 32000 (C), 40400 (D), 50000 (E) for $\operatorname{Re}=1 \times 10^{5}$ at $\alpha=8^{\circ}$ were compared to ensure grid independence of the calculations and finally the 32000 grids was chosen since difference of the results of $C_{L}$ values were negligible after this grid size as shown Figure 6.

\section{Numerical Method and Boundary Conditions}

ANSYS FLUENT ${ }^{\mathrm{TM}}$ 12.1.2 software which is based on the finite volume method was used perform numerical calculations. The domain except the aerofoil was selected as pressure far field and no slip condition was applied to the aerofoil surface. All calculations were conducted on as density based, and steady-state solution. In the calculations implicit method for formulation, and second order upwind discretization in space was used for all parameters of the models. Solutions converged when all residuals reached to 10-5. A free stream turbulence level was used as $\mathrm{Tu}=1 \%$. In the numerical calculations, the $\mathrm{k}-\omega$ SST model 
Citation: Karasu I, Genç MS, Açikel HH (2013) Numerical Study on Low Reynolds Number Flows Over an Aerofoil. J Appl Mech Eng 2: 131. doi:10.4172/2168-9873.1000131
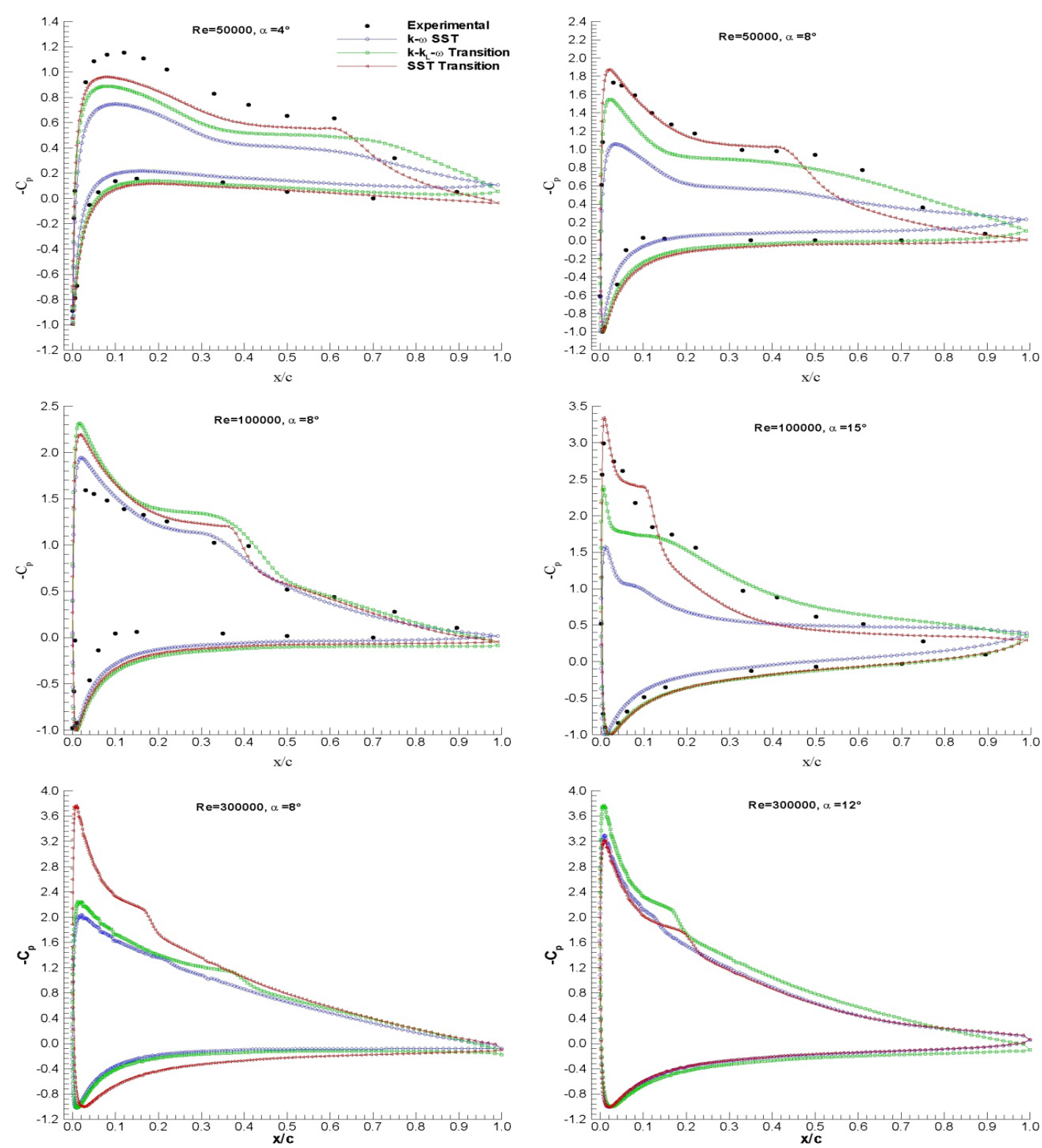

Figure 8: $C_{P}$ distributions over NACA 2415 aerofoil for different Reynolds numbers and angles of attack.

with low Re correction as turbulence model, and Transition $k-k_{\mathrm{L}}-\omega$ and $\mathrm{k}-\omega$ SST Transition models as two transition models were used. Genc et al. [8,9] was evaluated the turbulence and transition models and concluded that the k- $\omega$ SST turbulence model gave better results than the other turbulence models at low Re number flows. Therefore, the $\mathrm{k}-\omega$ SST model $k-\mathrm{k}_{\mathrm{L}}-\omega$ and $\mathrm{k}-\omega$ SST Transition models were chosen in this study. Furthermore, Genc et al. [9] was tested the performance of these transition models on the prediction of flow over the NACA2415 aerofoil at Re number of $2 \times 10^{5}$; and showed the success of the transition models. Moreover, the performance of the low Re number turbulence model and the transition models should be investigated at lower Reynolds numbers, and the aim of this study is to indicate the prediction capability of the low Re number turbulence model and the transition models at different and lower Reynolds numbers such as $0.5 \times 10^{5}, 1 \times 10^{5}$ and $3 \times 10^{5}$.

\section{The Summary of Previous Experimental Studies}

The experiments were carried out in a low speed wind tunnel. The free stream turbulence intensity of the wind tunnel is lower than $0.7 \%$ at lowest speed [15]. A NACA2415 aerofoil with a chord of $\mathrm{c}=180 \mathrm{~mm}$ and a span of $\mathrm{b}=280 \mathrm{~mm}$ was used in experiments. Oil flow visualization technique was employed for the flow visualization because this technique was simple to apply and effective to see flow conditions. A pitot-static tube, a scanivalve, a pressure transducer and a NACA2415 aerofoil with 24 pressure taps on upper and lower surfaces were used for the pressure measurements. In the pressure measurement experiments a computer-controlled data acquisition system was used. The pressure was measured by using Honeywell 163PC01D75 model differential pressure transducers with a pressure range of $623 \mathrm{~Pa}$. However, as this pressure range was not enough for the measurement of 
Citation: Karasu I, Genç MS, Açikel HH (2013) Numerical Study on Low Reynolds Number Flows Over an Aerofoil. J Appl Mech Eng 2: 131. doi:10.4172/2168-9873.1000131

Page 5 of 7
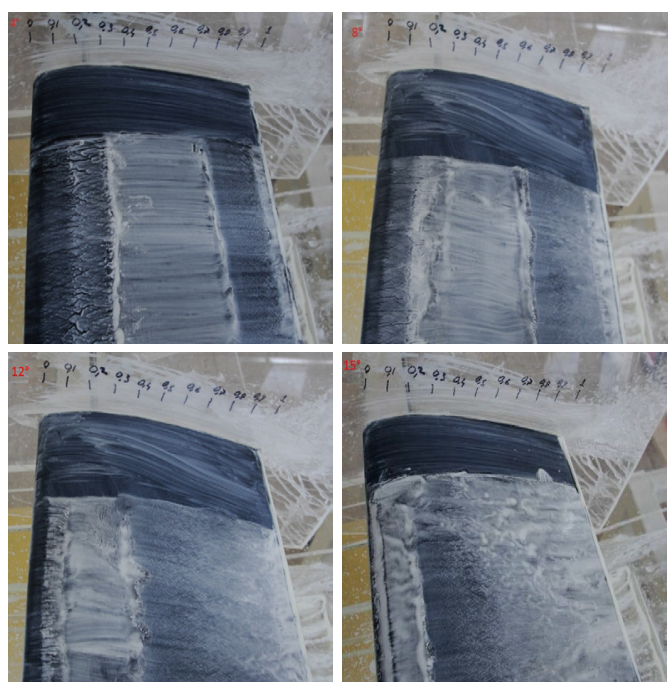

Figure 9: Experimental oil flow visualization results for $\mathrm{Re}=1 \times 10^{5}$ at a) $\left.\left.\left.\alpha=4^{\circ}, b\right) \alpha=8^{\circ}, c\right) \alpha=12^{\circ}, d\right) \alpha=15^{\circ}[15-16]$.
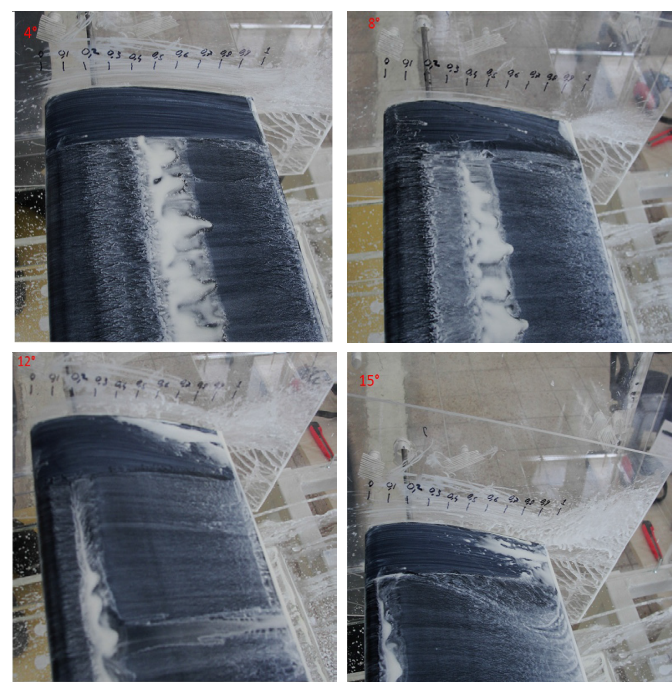

Figure 10: Experimental oil flow visualization results for $\operatorname{Re}=3 \times 10^{5}$ at a) $\left.\alpha=4^{\circ}, b\right) \alpha=8^{\circ}$, c) $\left.\alpha=12^{\circ}, d\right) \alpha=15^{\circ}[15-16]$.

\begin{tabular}{|c|c|c|c|c|c|c|c|c|c|}
\hline$\alpha$ & Model & $X_{s}$ & $x_{r}$ & $\mathrm{~L}_{\mathrm{b}}$ & $\alpha$ & Model & $x_{s}$ & $X_{r}$ & $\mathrm{~L}_{b}$ \\
\hline \multicolumn{10}{|c|}{$\mathrm{Re}=0.5 \times 10^{5}$} \\
\hline \multirow{4}{*}{$a=4^{\circ}$} & Experimental & 0.4 & 0.85 & 0.45 & \multirow{4}{*}{$a=10^{\circ}$} & Experimental & 0.2 & 0.6 & 0.4 \\
\hline & k-w SST & 0.3 & - & - & & k-w SST & 0.1 & - & - \\
\hline & $\mathrm{k}-\mathrm{k}_{\mathrm{L}}-\omega$ Transition & 0.35 & 0.95 & 0.6 & & $k-k_{L}-\omega$ Transition & 0.1 & - & - \\
\hline & SST Transition & 0.35 & 0.85 & 0.5 & & SST Transition & 0.15 & 0.5 & 0.35 \\
\hline \multirow{4}{*}{$a=8^{\circ}$} & Experimental & 0.25 & 0.75 & 0.5 & \multirow{4}{*}{$a=12^{\circ}$} & Experimental & 0.15 & 0.55 & 0.4 \\
\hline & $\mathrm{k}-\omega \mathrm{SST}$ & 0.2 & - & - & & k-w SST & 0.12 & - & - \\
\hline & $\mathrm{k}-\mathrm{k}_{\mathrm{L}}-\omega$ Transition & 0.15 & 0.95 & 0.8 & & $\mathrm{k}-\mathrm{k}_{\mathrm{L}}-\omega$ Transition & 0.12 & - & - \\
\hline & SST Transition & 0.25 & 0.65 & 0.4 & & SST Transition & 0.12 & 0.45 & 0.33 \\
\hline \multicolumn{10}{|c|}{$\mathrm{Re}=1 \times 10^{5}$} \\
\hline \multirow{4}{*}{$a=4^{\circ}$} & Experimental & 0.3 & 0.72 & 0.42 & \multirow{4}{*}{$a=12^{\circ}$} & Experimental & 0.12 & 0.42 & 0.3 \\
\hline & $k-\omega$ SST & 0.4 & 0.62 & 0.22 & & $k-\omega$ SST & 0.06 & 0.2 & 0.14 \\
\hline & $k-k_{L}-\omega$ Transition & 0.35 & 0.78 & 0.43 & & $k-k_{L}-\omega$ Transition & 0.04 & 0.2 & 0.16 \\
\hline & SST Transition & 0.32 & 0.7 & 0.38 & & SST Transition & 0.08 & 0.22 & 0.14 \\
\hline \multirow{4}{*}{$a=8^{\circ}$} & Experimental & 0.2 & 0.6 & 0.4 & \multirow{4}{*}{$a=15^{\circ}$} & Experimental & 0.05 & 0.2 & 0.15 \\
\hline & k-w SST & 0.16 & 0.5 & 0.34 & & $k-\omega S S T$ & 0.04 & 0.14 & 0.1 \\
\hline & $k-k_{L}-\omega$ Transition & 0.14 & 0.5 & 0.36 & & $k-k_{L}-\omega$ Transition & 0.02 & 0.5 & 0.48 \\
\hline & SST Transition & 0.2 & 0.5 & 0.3 & & SST Transition & 0.04 & 0.14 & 0.1 \\
\hline \multicolumn{10}{|c|}{$\mathrm{Re}=3 \times 10^{5}$} \\
\hline \multirow{4}{*}{$a=4^{\circ}$} & Experimental & 0.35 & 0.6 & 0.25 & \multirow{4}{*}{$a=12^{\circ}$} & Experimental & 0.15 & 0.28 & 0.13 \\
\hline & $k-\omega$ SST & - & - & - & & $k-\omega$ SST & 0.1 & 0.15 & 0.05 \\
\hline & $k-k_{L}-\omega$ Transition & 0.35 & 0.75 & 0.4 & & $\mathrm{k}-\mathrm{k}_{\mathrm{L}}-\omega$ Transition & 0.1 & 0.21 & 0.11 \\
\hline & SST Transition & 0.4 & 0.8 & 0.4 & & SST Transition & 0.13 & 0.26 & 0.13 \\
\hline \multirow{4}{*}{$a=8^{\circ}$} & Experimental & 0.3 & 0.45 & 0.15 & \multirow{4}{*}{$a=15^{\circ}$} & Experimental & 0.05 & 0.15 & 0.1 \\
\hline & $\mathrm{k}-\omega \mathrm{SST}$ & - & - & - & & $\mathrm{k}-\omega \mathrm{SST}$ & 0.05 & 0.08 & 0.03 \\
\hline & $\mathrm{k}-\mathrm{k}_{\mathrm{L}}-\omega$ Transition & 0.25 & 0.45 & 0.2 & & $k-k_{L}-\omega$ Transition & 0.05 & 0.12 & 0.07 \\
\hline & SST Transition & 0.1 & 0.2 & 0.1 & & SST Transition & 0.05 & 0.14 & 0.09 \\
\hline
\end{tabular}

Table 1: Experimental and numerical laminar separation bubble locations at different Reynolds numbers and angles of attack.

pressure difference over the aerofoil at $\mathrm{Re}=3 \times 10^{5}$ experimental pressure distributions for $\mathrm{Re}=3 \times 10^{5}$ could not be obtained. For measuring the lift and drag forces on the aerofoil, an external three-component loadcell system was used $[15,16]$. The force data was collected at a sampling frequency of $1000 \mathrm{~Hz}$ over $120 \mathrm{~s}$. Mean forces and moment and their coefficients were calculated using Microsoft Excel Software. The detailed information can be found in the References 15 and 16.

\section{Results}

In the experiments, the stall angle was $12^{\circ}, 13^{\circ}$ and $15^{\circ}$ for $\operatorname{Re}=0.5 \times 10^{5}, \operatorname{Re}=1 \times 10^{5}$ and $\operatorname{Re}=3 \times 10^{5}$, respectively (Figure 7). In the numerical results, the prediction of the lift coefficient of the models gave the different results and the $\mathrm{k}-\mathrm{k}_{\mathrm{L}}-\omega$ Transition model predicted more successfully the lift and drag coefficients, however all models under predicted the coefficients at $\mathrm{Re}=0.5 \times 10^{5}$. 
Citation: Karasu I, Genç MS, Açikel HH (2013) Numerical Study on Low Reynolds Number Flows Over an Aerofoil. J Appl Mech Eng 2: 131. doi:10.4172/2168-9873.1000131

Page 6 of 7

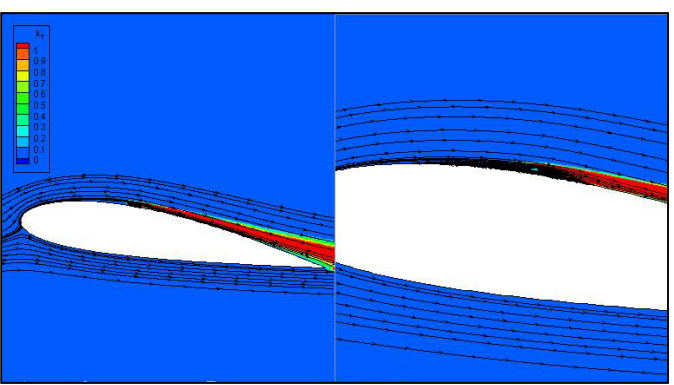

a)

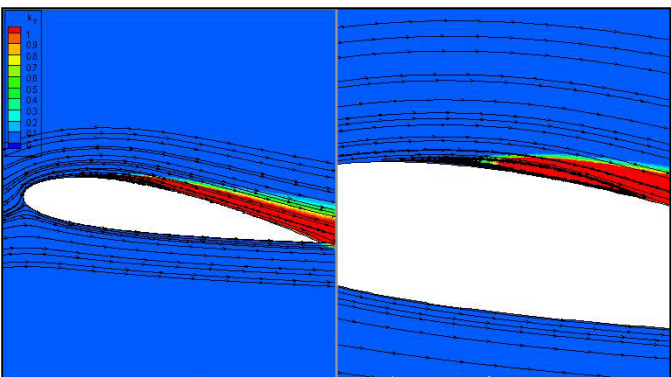

b)

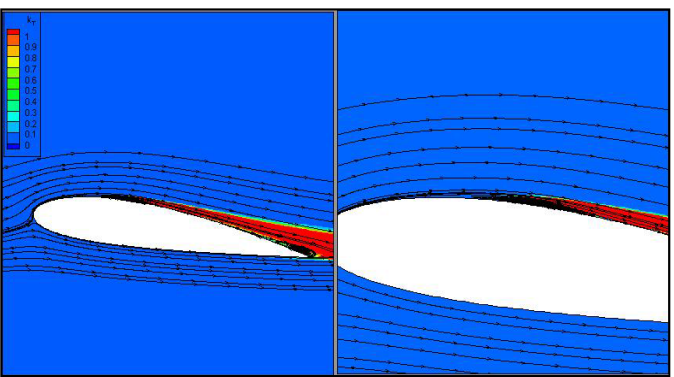

Figure 11: Stream traces and $k_{T}$ contours at $\operatorname{Re}=1 \times 10^{5}$ and $\alpha=8^{\circ}$; a) k- $\omega$ SST Transition, b) k-k $-\omega$ Transition, c) k- $\omega$ SST.

For the computational investigation of pressure distribution and flow phenomena over the NACA2415 aerofoil, two angles of attack for pre-stall condition $\left(4^{\circ}, 8^{\circ}\right)$ and an angle of attack near stall condition $\left(12^{\circ}\right)$ and an angle of attack for post stall condition $\left(15^{\circ}\right)$ were chosen. Figure 8 shows the experimental [15] and the numerical results of $\mathrm{Cp}$ distribution over the aerofoil at different angels of attack, and Figure 9 and 10 indicate experimental oil flow visualization results for the angles of attack of $4^{\circ}, 8^{\circ}, 12^{\circ}$ and $15^{\circ}$ at $\operatorname{Re}=1 \times 10^{5}$ and $\operatorname{Re}=3 \times 10^{5}$. The results of the experiments of pressure coefficients and oil-flow visualization provide to see the formation and progress of the laminar separation bubble, transition and re-attached flow. In the oil-flow visualization experiments, the dense area of pigment points out where the flow has decelerated, which correlates with the point, at which the flow separation and turbulent reattachment occur.

In Figure 8, at $\mathrm{Re}=0.5 \times 10^{5}$ the turbulence and transition models predicted the pressure coefficient values lower than the experiments while at $\mathrm{Re}=1 \times 10^{5}$ the transition models gave the better results. At lower Re numbers, the flow includes the more viscous forces which affect adversely the flow and cause flow separation to occur, therefore the numerical simulation is too difficult at lower Re number flows. Furthermore the low Re number turbulence model and transition model are successful on laminar separation bubble prediction although the bubble length and location are not predicted correctly. Consequently, as seen in Figures 8-10, as angle of attack increases, laminar separation bubble moves towards to leading edge and length of the laminar separation bubble decreases.
Table 1 shows the Separation Point $\left(\mathrm{X}_{\mathrm{S}}\right)$, the Reattachment Point $\left(\mathrm{X}_{\mathrm{R}}\right)$, and the Bubble Length $\left(\mathrm{L}_{\mathrm{b}}\right)$ for numerical and experimental studies. Because of the limited numbers of pressure taps on the suction side of the aerofoil (15 taps), the some locations of the $\mathrm{X}_{S}$ and $\mathrm{X}_{\mathrm{R}}$, and $\mathrm{L}_{\mathrm{B}}$ were determined by the help of oil visualization experiments. All locations were calculated via dividing the location by the chord of the aerofoil to obtain dimensionless numbers. Both transition models showed good agreement for the $\mathrm{X}_{\mathrm{S}}$ and $\mathrm{X}_{\mathrm{R}}$, and $\mathrm{L}_{\mathrm{b}}$ at $4^{\circ}, 8^{\circ}, 10^{\circ}$ and $12^{\circ}$ for $\mathrm{Re}=0.5 \times 10_{5}$ but the $\mathrm{k}-\omega \mathrm{SST}$ turbulence model did not predict the $\mathrm{X}_{\mathrm{R}}$ and $\mathrm{L}_{\mathrm{b}}$. Generally, the transition models are more successful than the $\mathrm{k}-\omega$ SST turbulence model on prediction the $\mathrm{X}_{S}$ and $\mathrm{X}_{\mathrm{R}}$, and $\mathrm{L}_{\mathrm{B}}$.

Figures 11 and 12 shows numerical stream traces and turbulent Kinetic Energy $\left(\mathrm{k}_{\mathrm{T}}\right)$ contours over the NACA2415 aerofoil at the angle of attack of $8^{\circ}$ at $\mathrm{Re}=1 \times 10_{5}$ and $\mathrm{Re}=3 \times 10_{5}$. The laminar separation bubbles predicted by the turbulence and transition models can be seen clearly. In the Laminar Part $\mathrm{k}_{\mathrm{T}}$ is minimum (0), after the transition completes $\mathrm{k}_{\mathrm{T}}$ starts to increase and goes on increasing. By means of the increase in the $\mathrm{k}_{\mathrm{T}}$ after the transition point, the flow has gained the kinetic energy and overcomes the adverse pressure gradient and a subsequent turbulent reattachment happens. In this way, the bubble is trapped under the separated shear layer between the separated and reattachment points.

\section{Conclusions}

In this study, the performance of the k- $\omega$ SST Transition, the $k-k_{L}-\omega$

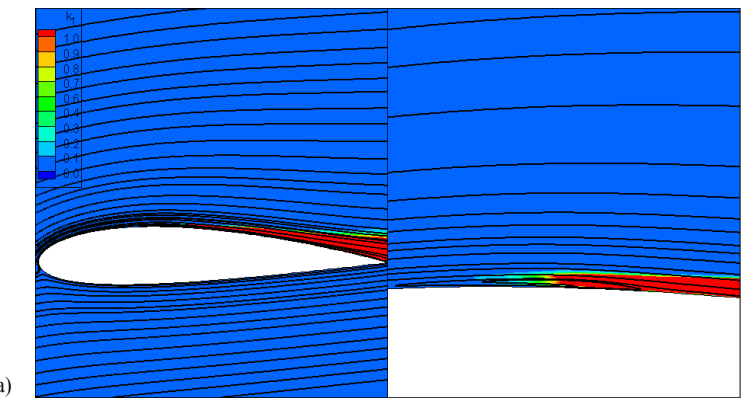

b)

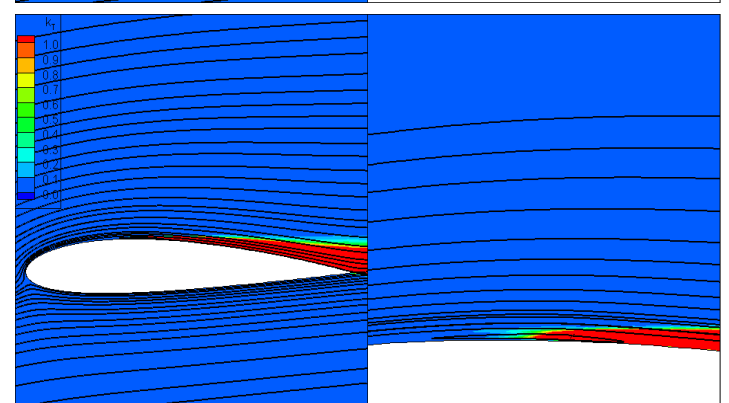

c)

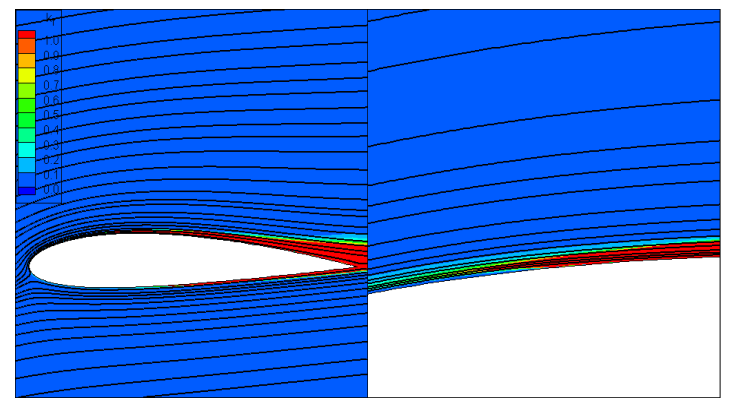

Figure 12: Stream traces and $\mathrm{k}_{\mathrm{T}}$ contours at $\mathrm{Re}=3 \times 10^{5}$ and $\alpha=8^{\circ} ; \mathrm{a}$ ) k- $\omega$ SST Transition, b) k- $k_{L}-\omega$ Transition, c) k- $\omega$ SST. 
Citation: Karasu I, Genç MS, Açikel HH (2013) Numerical Study on Low Reynolds Number Flows Over an Aerofoil. J Appl Mech Eng 2: 131. doi:10.4172/2168-9873.1000131

Page 7 of 7

Transition and the k- $\omega$ SST Transition models were investigated for predicting the laminar separation bubbles over a NACA 2415 aerofoil on various cases of angles of attack and Reynolds numbers. Lower Re numbers higher the viscous forces generated. Higher viscous forces affect the flow adversely and cause flow separation to occur, therefore the numerical simulation is relatively more difficult at lower Re number flows. Furthermore the low Re number turbulence model and transition models are both successful on prediction of laminar separation bubble, although the bubble length and location is not predicted correctly. The numerical results were showed that the flow gained kinetic energy because of the increase on the $\mathrm{kT}$ after the transition point and overcame the adverse pressure gradient and a subsequent turbulent reattachment occurred. Moreover, as seen in the results of numerical and experimental pressure distribution and oil-flow visualization experiment results, as angle of attack increases, laminar separation bubble moves towards to leading edge and length of the laminar separation bubble decreases. Consequently, the transition models are more successful than the $\mathrm{k}-\omega$ SST turbulence model on prediction the laminar separation bubble and low Re number flow.

\section{Acknowledgements}

The authors would like to acknowledge funding from the Scientific and Technological Research Council of Turkey (TÜBITAK) under the Project no: $110 \mathrm{M} 068$, the Scientific Research Projects Unit of Erciyes University under the contract no: FBA-10-3355, FBY-10-3369 and FBY-11-3516

$\begin{array}{ll}\text { Nomenclature } & \\ \alpha & \text { angle of attack } \\ C & \text { chord length } \\ b & \text { span length } \\ C_{D} & \text { drag coefficient } \\ C_{L} & \text { lift coefficient } \\ C_{p} & \text { pressure coefficient } \\ k_{T} & \text { turbulence kinetic energy } \\ L_{B} & \text { bubble length } \\ X / C & \text { ratio of the position on aerofoil with chord length } \\ X_{S} & \text { separation point } \\ X_{R} & \text { reattachment point }\end{array}$

\section{References}

1. Roberts WB (1980) Calculation of Laminar Separation Bubbles and Their Effect on Airfoil Performance. AIAA J 18: 25-31.

2. Van Dam, Holmes BJ (1988) Boundary-Layer Transition Effects on Airplane Stability and Control. J Aircraft 25: 702-709.

3. Ducoin A, Astolfi JA, Gober ML (2012) An experimental study of boundary-layer transition induced vibrations on a hydrofoil. J Fluid Struct 32: 37-51.

4. Horton HP (1968) Laminar Separation Bubbles in Two and Three Dimensional Incompressible Flow. University of London, UK.

5. Gaster M (1967) The Structure and Behaviour of Laminar Separation Bubbles. Aeronautical Research Council Reports and Memoranda.

6. Hu H, Zifeng Yang (2008) An Experimental Study of the Laminar Flow Separation on a Low-Reynolds-Number Airfoil. J Fluid Eng 130.

7. Rinoie K, Okuno M, Sunada Y (2009) Airfoil Stall Suppression by Use of a Bubble Burst Control Plate. AIAA J 47: 322-330.

8. Genc MS, Lock GD, Kaynak U (2008) An Experimental and Computational Study of Low Re Number Transitional Flows over an Aerofoil with Leading Edge Slat. 8th AIAAAviation Technology, Integration and Operations Conference, 1419 September, Alaska, USA.

9. Genc MS, Kaynak U, Yapici H (2011) Performance of transition model for predicting low $\mathrm{Re}$ aerofoil flows without/with single and simultaneous blowing and suction. Eur J Mech B-Fluid 30: 218-235.

10. Catalano P, Tognaccini $R$ (2011) RANS analysis of the low-Reynolds number flow around the SD7003 airfoil. Aerosp Sci Technol 15: 615-626.

11. Sanders DD, O'Brien WF, Sondergaard R, Polanka MD, Rabe DC (2010) Predicting Separation and Transitional Flow in Turbine Blades at Low Reynolds Numbers-Part I: Development of Prediction Methodology. J Turbomach 133: 1-10.

12. Catalano $P$, Tognaccini $R$ (2010) Turbulence modeling for low Reynolds number flows. AIAA J 48: 1673-1685.

13. Chitta V, Dhakal TP, Walters DK (2012) Prediction of Aerodynamic Characteristics for Elliptic Airfoils in Unmanned Aerial Vehicle. Low Reynolds Number Aerodynamics and Transition 59-78.

14. Ibrahim M, Kartuzova O, Volino RJ (2008) Experimental and Computational Investigations of Separation and Transition on a Highly Loaded Low-Pressure Turbine Airfoil: Part 1 - Low Freestream Turbulence Intensity," ASME paper IMECE2008-68879. Presented at the ASME, IMECE, Boston, Maschueseets, USA.

15. Genc MS, Karasu I, Acikel HH (2012) An experimental study on aerodynamics of NACA2415 aerofoil at low Re numbers. Experimental Thermal and Fluid Science 39: 252-264.

16. Karasu I (2011) Experimental and numerical investigations of transition to turbulence and laminar separation bubble over aerofoil at low Reynolds number flows. Graduate School of Natural and Applied Sciences, Erciyes University, Kayseri, Turkey. 